\title{
Seasonal endocrine cycles in the European hedgehog, Erinaceus europaeus
}

\author{
P. A. Fowler* \\ Department of Zoology, University of Aberdeen, Aberdeen AB9 2TN, U.K.
}

\begin{abstract}
Summary. Adult hedgehogs, maintained in captivity under natural environmental conditions of photoperiod and ambient temperature, were bled monthly. Plasma was assayed for melatonin, testosterone, prolactin, thyroxin, $\beta$-endorphin and both plasma and urine for cortisol. Melatonin concentrations followed a circannual pattern, maximal between November and February at photoperiods less than 10L:14D, which is suggested as a key photoperiod. $\beta$-Endorphin concentrations were maximal between March and September, coinciding with the reproductively active season of the hedgehog. Prolactin values were elevated during hibernation, indicating continued hypothalamo-pituitary axis activity. Testosterone and thyroxin levels were high between February and July and February and August respectively. During spring thyroxin concentrations rose 1 month later in females than males, reflecting the earlier arousal of the males from hibernation. There were no marked seasonal cycles of plasma or urinary cortisol. The results indicate photoperiod as the main factor in regulating hedgehog seasonality, with melatonin, $\beta$-endorphin and prolactin important in the timing of reactivation of reproduction. Sexual differences in hedgehogs suggests environmental fine tuning of endogenous cycles, males being ready to inseminate females early in spring, while females only begin full breeding activity when conditions are suitable.
\end{abstract}

Keywords: European hedgehog; seasonal endocrine cycles

\section{Introduction}

Reproductive and hibernal cycles vary in the extent to which they overlap (Wimsatt, 1969), hibernation limiting the duration of the breeding season. Female hedgehogs, Erinaceus europaeus, at $54^{\circ} \mathrm{N}$ are anoestrous from October until April, when spontaneous ovulation and dioestrous cycling occurs (Deanesly, 1934). In England most pregnancies occur between May and September, few females breeding biannually, unlike females at $46^{\circ} \mathrm{N}$ in south-west France (Girod et al., 1967). During hibernation the endometrium proliferates and folliculogenesis begins (Walin et al., 1968) before permanent arousal.

The testes of male hedgehogs are fully active from April until the end of August at $54^{\circ} \mathrm{N}$ (Allanson, 1934). Despite variation (Saboureau \& Peyre, 1970), full testicular reactivation, with mature spermatocytes present in the epididymides, usually occurs before April in south-west France. Since peak plasma testosterone values are attained 1 month before full spermatogenesis (Saboureau, 1981; Dutourne \& Saboureau, 1983), returning to basal levels 1 month before seminiferous tubule regression, circulating testosterone concentrations are an accurate reproductive index. During the first half of hibernation spermatogenesis remains at the primary spermatocyte stage (Allanson, 1934; Saure, 1969), testicular reactivation recommencing from mid-hibernation

*Present address: Department of Bio-Medical Physics, University of Aberdeen, Aberdeen AB9 2ZD, U.K. 
(Saboureau, 1979), while the hedgehogs have low body temperatures for much of the time (Fowler, 1986).

There is histological evidence for annual cycles of plasma concentrations of luteinizing hormone (LH), follicle-stimulating hormone (FSH) (Girod \& Cure, 1965; Girod et al., 1967) and prolactin in male and female hedgehogs, the latter being antigonadotrophic in males (Girod $e t$ al., 1965). There is, however, no histological evidence for hibernal pituitary inactivity (Dubois \& Girod, 1967). Plasma thyroxin concentrations and adrenal endocrine function are also highly seasonal in the hedgehog (Saboureau et al., 1979a, b), the rapidly rising spring thyroxin values coinciding with increased frequency of spontaneous arousals from hibernation (Kristoffersson \& Soivio, 1964). Plasma cortisol and corticosterone levels, on the other hand, are maximal during the first half of hibernation, and minimal between January and May.

Ultrastructural changes in hedgehog pinealocytes correlate with seasonal reproductive changes (Pevet \& Saboureau, 1974; Pevet, 1975), melatonin having an anti-gonadotrophic effect during summer (Saboureau, 1973). Experimental conditions of short days and low ambient temperatures, after spring reactivation, resulted in rapid involution, always followed by reactivation the following spring (Saboureau, 1981). These results suggest that the hedgehog is photorefractory in late summer and autumn, but highly photoperiodic in the timing of spring reactivation, endogenous cycles modified, but not abolished, by experimental conditions. Endogenous opioids are of particular interest in hibernators because of their suspected action as hibernation-induction triggers (Dawe, 1978; Oeltgen et al., 1981; Kulpa \& Hall, 1983) and as regulators of reproductive cycles (Ebling \& Lincoln, 1985; Roberts et al., 1985; Brooks et al., 1986).

The aims of the present study were: (1) to characterize circannual changes in concentrations of plasma testosterone, melatonin, $\beta$-endorphin, prolactin, thyroxin and urinary and plasma cortisol, at $57^{\circ} \mathrm{N}$ in a model hibernator, the hedgehog; and (2) to study adaptations of annual endocrine cycles to hibernal and environmental influences, in particular, how the hypothalamo-pituitarygonad axis reactivates in animals undergoing deep hibernation.

\section{Materials and Methods}

\section{Animals and methods}

Animals. The hedgehogs were captured in Aberdeenshire, N.E. Soctland, at $57^{\circ} \mathrm{N}$, and were housed, in outdoor pens containing nest-boxes, at Culterty Field Station. Food, consisting of day old chicks, dog meal and tinned cat food, and water were provided ad libitum. The animals were undisturbed, apart from weekly weighing, and exposed to natural photoperiod, ambient temperature and precipitation. In 1982/83 and 1983/84 there were 4 males and 4 females per month and in 1984/85 there were 6 males and 6 females per month.

Blood sampling. Blood was collected either once per month, at mid-day (1982/3 and 1983/4), or twice per month, at $2 \mathrm{~h}$ after sunset and then $5 \mathrm{~h}$ after sunrise the following day (1984/5), from adult hedgehogs. Light anaesthesia with $5 \%$ halothane $/ \mathrm{O}_{2}$ (ICI Plc., Macclesfield, U.K.) preceded collection of 4-5-ml blood samples by cardiac puncture. The blood was mixed into heparinized tubes, centrifuged, and $1 \mathrm{ml}$ aliquants were stored at $-25^{\circ} \mathrm{C}$ within $1 \mathrm{~h}$.

Urine collection. Hedgehogs blood sampled in $1984 / 5$ were placed in rat metabolic chambers for up to $12 \mathrm{~h}$ between the 2 blood samples. A filtered funnel attached to the wire cage-floor directed the urine into $10 \mathrm{ml}$ specimen jars which were stored at $-25^{\circ} \mathrm{C}$ within $8 \mathrm{~h}$.

\section{Hormone assays}

Testosterone. Plasma testosterone concentrations in male hedgehogs were determined using a heterologous, double-antibody, radioimmunoassay previously described by Fowler \& Racey (1987). Minimum distinguishable testosterone levels were $0.05 \mathrm{ng} / \mathrm{ml}$ and intra- and inter-assay coefficients of variation were $10.8 \%$ and $13.4 \%$ respectively.

Melatonin. In 1984/5 plasma melatonin concentrations were determined, using the heterologous double-antibody assay described by Webley et al. (1985), at the Institute for Hormone and Fertility Disorders, Hamburg, F.R.G. The primary antiserum was sheep anti-melatonin (Guildhay Antiserum, University of Surrey, Guildford, U.K.) with donkey anti-sheep/goat precipitating antibody (Antibody Production Unit, Law Hospital, Carluke, U.K.). Cross- 
reaction with 6-hydroxymelatonin, $\mathrm{N}$-acetyl-5-hydroxytryptamine and 5-hydroxytryptamine was $<0 \cdot 2 \%$. The minimum sensitivity of the assay was $9.6 \mathrm{pmol}$ melatonin/l. Hedgehog plasma dilutions closely paralleled the standard curve and the recovery of unlabelled melatonin from pooled hedgehog plasma was both linear and proportional. The intra- and inter-assay coefficients of variation were $7.3 \%$ and $8.5 \%$.

Prolactin. Plasma from 1982/3 and 1983/4 was assayed at the School of Agriculture, University of Aberdeen, using a heterologous, double-antibody assay with anti-prolactin raised in rabbits and a second donkey anti-rabbit antibody, based on the method described by Chesworth (1977). Dilutions of hedgehog plasma paralleled the standard curve and the recovery of unlabelled prolactin from hedgehog plasma was linear and proportional. Minimum detectable levels of prolactin were $0.75 \mathrm{ng} / \mathrm{ml}$. Cross-reactivity was $<0.1 \%$ with $\mathrm{LH}, \mathrm{FSH}, \mathrm{GH}$ and TSH. Intra- and inter-assay coefficients of variation were $6.8 \%$ and $10.9 \%$ respectively.

Plasma from 1984/5 was assayed for prolactin at the MRC Reproductive Biology Unit, Edinburgh, using a heterologous double-antibody assay (McNeilly \& Friesen, 1978) because of the wide range of prolactin species that this assay detected successfully. The primary antiserum was raised in guinea-pigs with sheep anti-guinea-pig gammaglobulin as the precipitating antibody. Cross-reactivity with growth hormone, FSH, LH, TSH and placental lactogens was $<0.01 \%$. Hedgehog plasma and pituitary extract dilutions paralleled the standard curve, but the comparatively low levels of the latter indicated low cross-reactivity of the antibody with hedgehog prolactin. The amount of prolactin detectable at $90 \% \mathrm{~B} / \mathrm{Bo}$ was $0.3 \mathrm{ng} / \mathrm{ml}$ and the intra- and inter-assay coefficients of variation were $7 \cdot 1 \%$ and $11 \cdot 1 \%$ respectively.

$\beta$-Endorphin. Circulating levels of $\beta$-endorphin were determined at the MRC Reproductive Biology Unit, Edinburgh, using the assay described by Ebling \& Lincoln (1987). Because the assay required $2 \mathrm{ml}$ of plasma, hedgehog plasma samples pooled from at least 2 males and 2 females each month were used. The label was ${ }^{125} I$, the antiserum was raised in sheep, and the extraction efficiency was $79.0 \%$. Cross-reaction was $<0 \cdot 2 \%$ with $\alpha$-endorphin, $\gamma$-endorphin, met-enkephalin and dynorphin. The dilution of 2 hedgehog plasma pools was parallel to the standard curve and extracted sheep $\beta$-endorphin. The recovery of unlabelled $\beta$-endorphin from hedgehog plasma was linear and proportional. The intra- and inter-assay coefficients of variation were $12.3 \%$ and $18.6 \%$ respectively.

Thyroxin. Plasma thyroxin levels were determined at the School of Agriculture, University of Aberdeen, using a single sheep anti-thyroxin antibody radioimmunoassay based on the method described by Ratcliffe et al. (1974). Polyethylene glycol separation of thyroxin was necessary. Cross-reaction with $3,5,3^{\prime}$-triiodothyronine was $<2 \cdot 0 \%$. Dilution of hedgehog plasma was parallel to the standard curve and the recovery of unlabelled thyroxin from pooled hedgehog plasma was linear and proportional. The sensitivity of the assay was $0.6 \mathrm{ng} /$ tube and intra- and inter-assay coefficients of variation were $6 \cdot 8 \%$ and $12 \cdot 3 \%$.

Cortisol. Plasma cortisol was determined at the School of Agriculture, University of Aberdeen, using a single antibody RIA with sheep anti-cortisol (after Abraham, 1969; Henderson \& Chesworth, 1977). The assay label was ${ }^{3} \mathrm{H}$ and the efficiency of ether extraction was $79 \pm 2 \cdot 9 \%$. Cross-reactivity with corticosterone, cortisone, 21-deoxycortisone, 11-deoxycortisone, 11-deoxycorticosterone and dexamethasone was $<0.05 \%$, and $0.01 \%$ with oestradiol, testosterone and progesterone. Dilutions of hedgehog plasma paralleled the standard curve and the recovery of unlabelled cortisol from pooled hedgehog plasma was linear and proportional. Sensitivity of the assay was $12.3 \mathrm{pg} /$ tube, with intra- and inter-assay coefficients of variability at $5.7 \%$ and $9.8 \%$ respectively. Urinary free-cortisol was determined by a commercial RIA kit, Cortisol ${ }^{125}$ I (Farmos Diagnostica, Farmos Group Ltd, Turku, Finland). The antiserum was rabbit anti-cortisol and the specified cross-reactivities were only $>1 \%$ with prednisolone, corticosterone, 11 -deoxycortisol and $5 \beta$-dihydrocortisol. Intra- and inter-assay coefficients of variability were $2 \cdot 2 \%$ and $5 \cdot 3 \%$ respectively.

\section{Statistical analysis}

Differences between hormone values were tested by analysis of variance (ANOVA) or the Mann-Whitney test (Zar, 1984). Relationships between variables were compared by simple linear correlations, $r$ (Snedecor \& Cochran, 1980). Rhythmicity of changes in variables was tested using least-squares cosine curves (Halberg et al., 1967; Shiotsuka $e t$ al., 1974) and the deviations from cosine curves were quantified by fitting sine least-squares curves and converting the arctangent of the time-interval. Unless otherwise stated means are presented as \pm s.e.m.

\section{Results}

\section{Body mass cycle}

The circannual pattern of changes in body mass of male and female hedgehogs was marked, with weight loss during hibernation (Fig. 1), reaching minimum levels, about $30 \%$ below maximum levels, between January and April. Rapid recovery of body mass occurred in spring, with peak weights attained between July and September, before the onset of hibernation. Both males and females deviated from strict 12-month cycles by $<27$ days/12 months (cosine regression, 
$P<0.001$ ). On average males were $12.8 \pm 2.1 \%$ heavier than females (Mann-Whitney, $P<0.01$ ), although there was no significant difference $(r, P>0.05)$ between the body mass cycles of males and females.

\section{Testosterone}

Plasma testosterone levels showed a marked circannual pattern in the plasma of male hedgehogs, with no significant difference (Mann-Whitney, $P>0.05$ ) between day and night samples (Fig. 2). The cycles for the 3 years showed no significant differences $(r, P<0.001)$, with plasma testosterone concentrations rising rapidly in spring and peaking between February and April. There was a tendency for a mid-summer trough in testosterone concentrations, but this was not significant (ANOVA, $P>0.05$ ). In all 3 years testosterone fell sharply to basal levels in August, remaining low through the first half of winter.

Cosine least-squares curve-fitting showed that the plasma testosterone cycle deviated by 12 days/year compared to the calculated cycle (cosine-regression, $P<0.001$ ), with most deviation occurring in the spring when testosterone values rose abruptly. The circannual testosterone cycle correlated very closely ( $r, P<0.001)$ with the monthly rate of change of photoperiod (Fig. 3 ), only the July values, at the end of the male's breeding season, deviating from the direct relationship.

\section{Melatonin}

There were no significant differences between night or day plasma melatonin values (Mann-Whitney, $P>0.05$ ) or between melatonin concentrations in males and females (MannWhitney, $P>0.05)$, which had closely correlated annual cycles $(r, P<0.001)$. Peak levels were recorded between November and February (Fig. 4), while basal concentrations were observed during summer and early autumn. Plotting mean monthly plasma melatonin concentrations against photoperiod showed clearly (Fig. 5) that at shorter than 10L:14D photoperiods (coinciding with the period between November to February) melatonin concentrations were significantly higher (ANOVA, $P<0.001$ ) than when there was more than $10 \mathrm{~h}$ light per day. Plasma melatonin concentrations fell proportionally with increasing daylength $(r, P<0.01)$ when photoperiod was longer than $10 \mathrm{~L}: 14 \mathrm{D}$.

\section{Prolactin}

The low cross-reactivity of the assays for hedgehog prolactin resulted in significant variation in concentrations of prolactin detected (Mann-Whitney, $P<0.001$ ). There was however no significant difference (Mann-Whitney, $P>0.05$ ) between circulating values of prolactin in male and female hedgehogs, and in 1984/5 no significant difference between day and night concentrations (Mann-Whitney, $P>0.05$ ). Circannual changes in prolactin titres of males and females each year were similar $(r, P<0.01)$. To accommodate the variability between years, the prolactin concentrations were year-normalized by dividing each measured plasma prolactin titre by the mean value for that particular year. Prolactin values were significantly elevated during hibernation, compared to summer concentrations (ANOVA, $P<0.001$ ). Overall quarterly mean results from all 3 years are shown in Fig. 8.

\section{$\beta$-Endorphin}

The results in Fig. 6 show overall values for each month. There was a marked circannual cycle of circulating $\beta$-endorphin titres, with concentrations being significantly higher (ANOVA, $P<0.001)$ between March and September than during winter, coinciding with the period of greatest metabolic and reproductive activity. The dip in $\beta$-endorphin concentrations during mid-summer was not significant (ANOVA, $P>0.05$ ). 


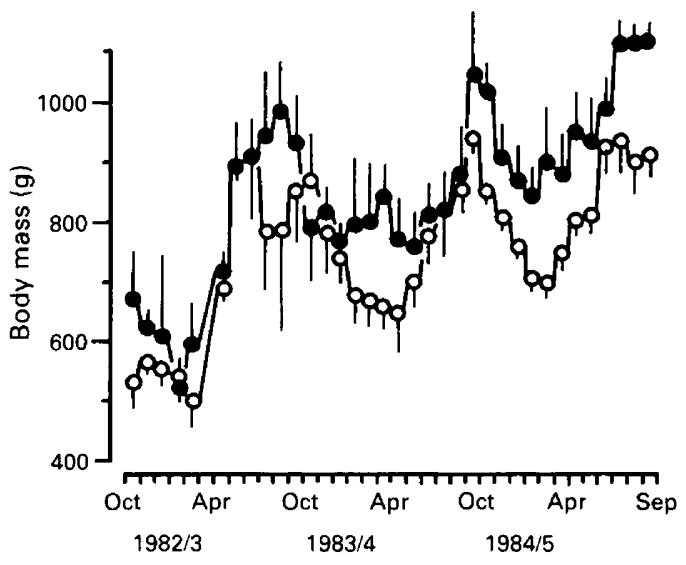

Fig. 1. Circannual body mass cycles in male $(\bullet)$ and female $(O)$ hedgehogs, 1982 to 1985. Values are mean \pm s.e. for $4-6$ animals/month.

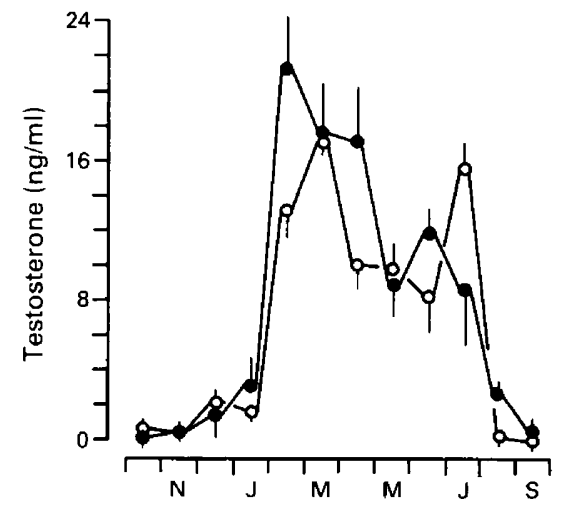

Fig. 2. Circannual cycle of plasma testosterone in male hedgehogs. Blood samples were taken $2 \mathrm{~h}$ after sunset $(\bullet)$ or $5 \mathrm{~h}$ after sunrise $(O)$. Values are mean \pm s.e. for $4-6$ animals/month.

\section{Thyroxin}

Little difference between male and female concentrations of circulating thyroxin (MannWhitney, $P>0.05)$ occurred, with similar circannual cycles in males and females $(r, P<0.001)$. Both males and females had thyroxin values up to 12 times higher during the summer than during winter (ANOVA, $P<0.01$ ) and there was no significant difference between day and night concentrations (Mann-Whitney, $P>0.05$ ), although there was a tendency towards a biphasic peak in the summer thyroxin concentrations of female hedgehogs (Fig. 7). Plasma thyroxin values also rose and fell 1 month earlier, in spring and autumn respectively, in males compared to females.

\section{Cortisol}

The pattern of plasma and urinary cortisol in male and female hedgehogs was extremely variable, with differences between sexes (Mann-Whitney, $P<0.01$ ) and day and night concentrations in males (Mann-Whitney, $P<0.01$ ). Overall male and female and plasma and urinary 


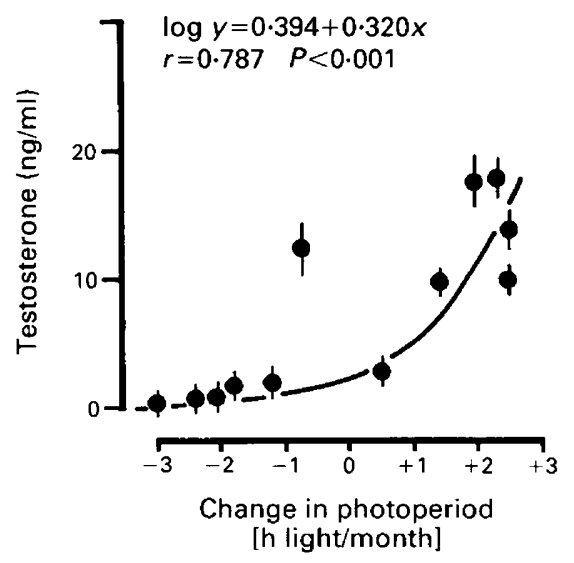

Fig. 3. Relationship between plasma testosterone concentration in male hedgehogs and the rate of change of photoperiod. Based on data from 1982 to 1985 . Values are mean \pm s.e. for $4-6$ animals/month.
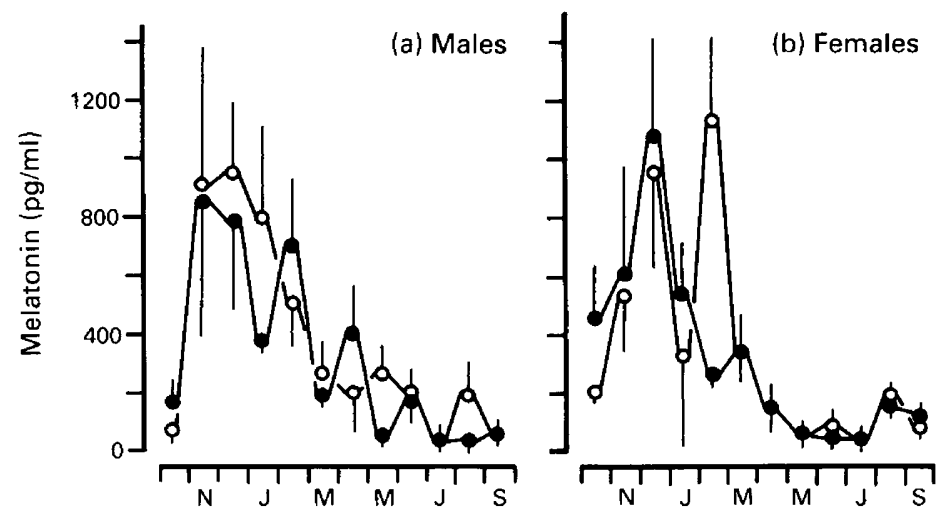

Fig. 4. Circannual plasma melatonin cycles in male (a) and female (b) hedgehogs. Blood samples were taken $2 \mathrm{~h}$ after sunset $(\bullet)$ or $5 \mathrm{~h}$ after sunrise $(O)$. Values are mean \pm s.e. for 4-6 animals/month.

changes in concentrations during the year were not similar $(r, P>0.05)$. Urine however, showed a significant (ANOVA, $P<0.05$ ) elevation in cortisol values during October/December compared to January/February. Neither plasma nor urinary cortisol correlated with plasma $\beta$-endorphin levels (ANOVA, $P>0.05$ ).

\section{Environmental and hormonal interactions}

The quarterly means of the body mass and hormonal values presented are shown in Fig. 8. Each sequence is repeated to allow clear comparison between variables. A prominent feature of the cycles shown is the winter/summer orientation, with peak concentrations tending to occur at extreme phases of photoperiod and ambient temperature.

The correlation betweeen physiological changes and environmental conditions (Table 1) revealed a difference between males and females in that some male cycles showed better correlation 


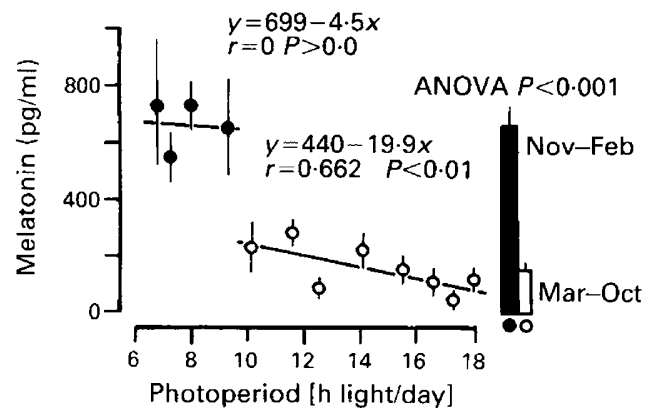

Fig. 5. Changes in circulating melatonin concentrations in male and female hedgehogs with photoperiod. Mean monthly values for months of shorter $(0)$ or longer $(O)$ photoperiod than 10L:14D. Values are mean \pm s.e. for 4-6 animals/month.

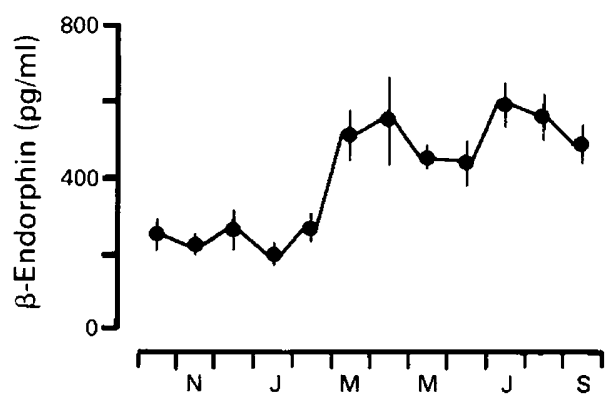

Fig. 6. Circannual cycle of plasma $\beta$-endorphin concentrations in pooled male and female hedgehog plasma samples. Pooled samples were used because of the large assay volume of plasma required. Values are mean \pm s.e. for 4-6 animals/month.

(a) Males

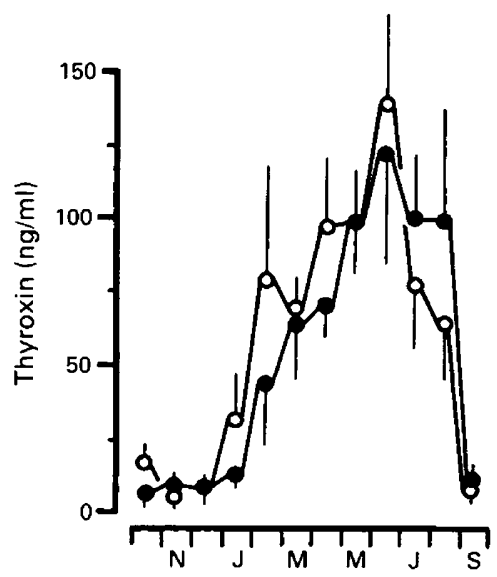

(b) Females

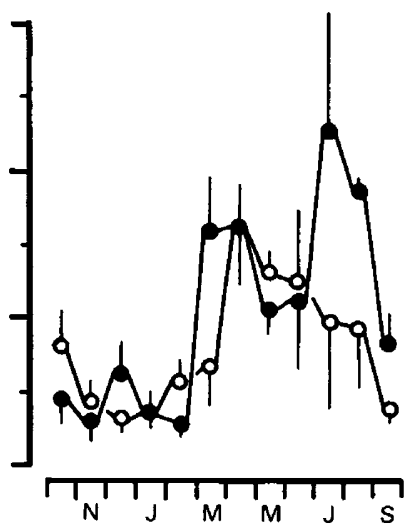

Fig. 7. Circannual plasma thyroxin cycles in male (a) and female (b) hedgehogs. Blood samples taken $2 \mathrm{~h}$ after sunset $(\odot)$ or $5 \mathrm{~h}$ after sunrise $(O)$. Values are mean \pm s.e. for $4-6$ animals/ month. 


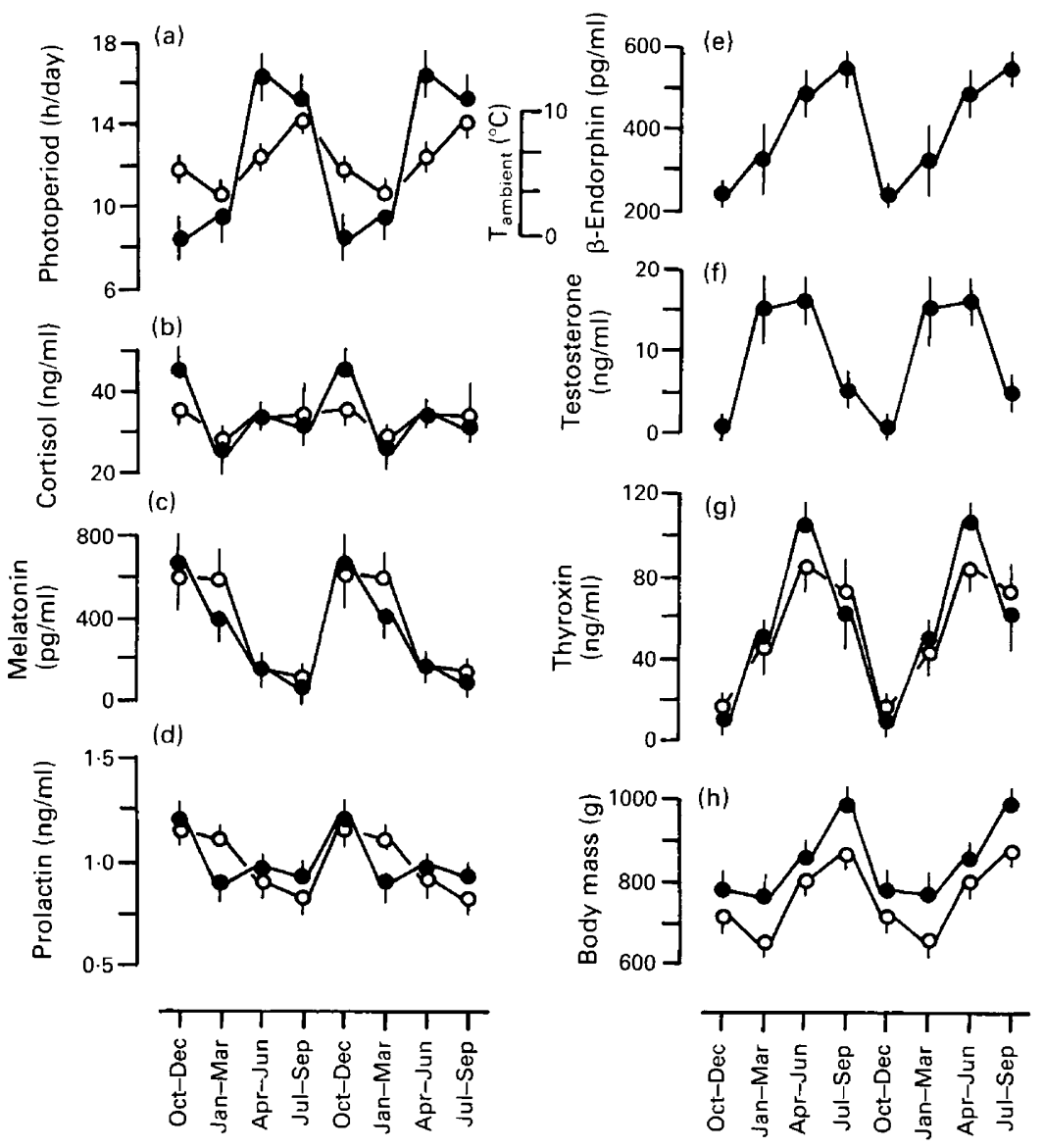

Fig. 8. Overall mean quarterly values for body mass, hormonal and environmental data. Each cycle is shown twice: (a) photoperiod $(\bullet)$ and ambient temperature $(\bigcirc)$, (b) urinary $(\bullet)$ and plasma $(O)$ cortisol, (c) melatonin in males $(\bullet)$ and females $(O)$, (d) prolactin in males $(\bullet)$ and females $(\mathrm{O})$, (e) $\beta$-endorphin, (f) testosterone, (g) thyroxin in males $(\mathrm{O})$ and females $(\mathrm{O})$, (h) body mass of males $(\bullet)$ and females $(O)$. Values are mean \pm s.e. for 4-6 animals/month.

with the rate of change in photoperiod, rather than with photoperiod itself, while some female cycles correlated better with ambient temperature than did male cycles. This is most clearly seen in the case of prolactin. However, in both males and females, body mass, plasma melatonin, thyroxin and $\beta$-endorphin cycles correlated closely with photoperiod and ambient temperature. Testosterone, body mass, thyroxin and $\beta$-endorphin were elevated during increasing or long daylength and higher ambient temperature, while melatonin and prolactin peaked with minimum photoperiod, when ambient temperatures were lowest.

Interactions betweeen the body mass and endocrine cycles (Table 2) clearly show that melatonin and thyroxin correlated with the other cycles most of all, while cortisol was unrelated to, and prolactin only poorly correlated with, other cycles. Body mass also showed good correlation with the hormonal cycles. Cycles which correlated well with environmental conditions tended to correlate with each other as well. Prolactin and testosterone were inversely related, prolactin concentrations of $>1.4 \mathrm{ng} / \mathrm{ml}$ coinciding with low testosterone titres. The highest thyroxin concentrations coincided with the period of most rapid body mass gain. 
Table 1. Correlations between seasonal cycles and environmental conditions in hedgehogs

\begin{tabular}{llcccc}
\hline & & & & Environmental condition \\
\multicolumn{1}{c}{ Cycle } & Sex & Photoperiod & $\mathrm{T}_{\text {ambient }}$ & $\begin{array}{c}\text { Change in } \\
\text { photoperiod }\end{array}$ & $\begin{array}{c}\text { Change in } \\
T_{\text {ambient }}\end{array}$ \\
\hline B-Endorphin & Both & $* * *$ & $* * *$ & NS & $* * *$ \\
Testosterone & Males & $* *$ & $*$ & $* * *$ & $* * *$ \\
Melatonin & Males & $* * *$ & $* * *$ & NS & $* *$ \\
& Females & $* * *$ & $* * *$ & NS & $* *$ \\
Prolactin & Males & NS & NS & $* *$ & $*$ \\
& Females & $* * *$ & $* * *$ & NS & $* *$ \\
Cortisol & Males & NS & NS & NS & NS \\
Thyroxin & Females & NS & $* *$ & NS & $*$ \\
Body mass & Males & $* * *$ & $* * *$ & NS & $* * *$ \\
& Females & $* * *$ & $* * *$ & $*$ & NS \\
& Males & $* * *$ & $* * *$ & $*$ & NS \\
\hline
\end{tabular}

${ }^{*} P<0.05 ;{ }^{* *} P<0.01 ;{ }^{* * *} P<0.001$.

Table 2. Correlations between hormonal and body mass seasonal cycles in hedgehogs

\begin{tabular}{|c|c|c|c|c|c|c|c|c|}
\hline \multirow[b]{2}{*}{ Cycle } & \multicolumn{2}{|c|}{ Body mass } & \multicolumn{2}{|c|}{ Melatonin } & \multirow{2}{*}{$\frac{\beta \text {-Endorphin }}{\text { Both }}$} & \multirow{2}{*}{$\begin{array}{c}\text { Testosterone } \\
\text { Male }\end{array}$} & \multicolumn{2}{|c|}{ Prolactin } \\
\hline & Male & Female & Male & Female & & & Male & Female \\
\hline Body mass & & & $* *$ & $* *$ & & & & \\
\hline$\beta$-Endorphin & $* *$ & * & $* *$ & $* *$ & & & & \\
\hline Testosterone & ** & & NS & & NS & & & \\
\hline Prolactin & NS & NS & $* *$ & NS & NS & * & & \\
\hline Thyroxin & * & $*$ & $* *$ & * & $* * *$ & ** & * & NS \\
\hline Cortisol & NS & NS & NS & NS & NS & NS & NS & NS \\
\hline
\end{tabular}

${ }^{*} P<0.05 ;{ }^{* *} P<0.01 ;{ }^{* * *} P<0.001$.

\section{Discussion}

The present study, at $57^{\circ} \mathrm{N}$, enables latitudinal comparisons with studies at $46^{\circ} \mathrm{N}$ in southwest France, and investigation of a specialized endocrine system. Blood sampling by anaesthesia and cardiac puncture may be stressful, although this should have declined as the hedgehogs became accustomed to repeated sampling. While there are no data concerning the effect of stress on hedgehog hormone levels, two factors mitigate against a significant effect: firstly, the process was rapid, $<3$ min from start to finish, and, secondly, plasma cortisol concentrations in the present study were no higher than those measured in plasma from undisturbed hedgehogs bearing carotid catheters (Saboureau et al., 1979b).

There was no measurement of target tissue uptake and peripheral metabolic clearance of the hormones investigated in the present study. In the hedgehog the efficiency of testosterone binding protein in plasma has an annual cycle opposite that of plasma testosterone concentrations (Saboureau et al., 1982). The peripheral metabolism of testosterone also fluctuates, but Saboureau \& Boissin (1983) concluded that in the hedgehog only the small summer dip in plasma testosterone concentrations was explained by increased metabolic clearance. Gustafson \& Damassa (1987) 
showed that, while sex-steroid binding proteins modulated the effects of circulating steroids, they in no way invalidated conclusions based on plasma concentrations of the hormones themselves. These studies suggest that, while target tissue uptake and metabolic clearance are important, the measurement of circulating concentrations of hormones remains valid in the investigation of physiological cycles and their regulation.

Plasma testosterone at $57^{\circ} \mathrm{N}$ shows a period of elevation 2 months shorter in duration than at $46^{\circ} \mathrm{N}$ (Saboureau \& Boissin, 1978; Saboureau \& Dutourne, 1981), rising and falling 1 month later and earlier respectively. This later reactivation, and earlier involution, is associated with the shorter summers at $57^{\circ} \mathrm{N}$, spermatogenesis occurring over a shorter period. The mid-summer reductions in testosterone concentrations in northeast Scotland are less profound than at $46^{\circ} \mathrm{N}$, reflecting a monophasic breeding season at $57^{\circ} \mathrm{N}$ (Deanesly, 1934; Kristiansson, 1984), unlike the biannual production of litters common in southwest France (Saboureau \& Castaing, 1985).

The circannual cycles of plasma thyroxin were similar at the two latitudes (Saboureau \& Boissin, 1978). However, as with testosterone, thyroxin concentrations were depressed for longer (September to January) than in southwest France (October to January), with peak levels occurring up to 2 months later. At both latitudes plasma concentrations of testosterone and thyroxin were closely correlated.

Saboureau et al. (1979a) found that concentrations of plasma cortisol and corticosterone peaked in December with a definite circannual cycle. However, the variability of both plasma and urine cortisol in northeast Scotland may be due to differences in RIA characteristics, since the cortisol/corticosterone ratio in hedgehogs is 28:1 (Boissin et al., 1975), and corticosterone was not assayed in the present study. Another potential source of difference is the timing of blood sampling since the circadian cycles of plasma cortisol altered during the year (Saboureau et al., 1979b).

The present study was the first in which plasma concentrations of melatonin and $\beta$-endorphin were determined in the European hedgehog, and represents the first attempt to characterize the circannual pattern of plasma prolactin concentrations in this species. The incremental nature of the body mass plots (Fig. 1) is a feature of adult hedgehogs in captivity (M. Saboureau, personal communication), and the characteristic circannual cycles remain.

Plasma prolactin concentrations were significantly (ANOVA, $P<0.001$ ) higher during winter (Fig. 8), indicating continued hypothalamo-pituitary activity during hibernation, although in another hibernator, the ground squirrel Citellus tridecemlineatus, the pituitary is lighter during winter (Hoffman \& Zarrow, 1958). Due to reduced cellular activity (Cameron \& Cleffmann, 1964) and hormone synthesis (Teravainen \& Saure, 1976) little gonadotrophin secretion can occur simultaneously with deep hibernation when hedgehog body temperatures may fall below $5^{\circ} \mathrm{C}$ for several days at a time (Fowler, 1986). Therefore, most secretory activity must occur during spontaneous arousals, which increase in frequency during the second half of hibernation (Kristoffersson \& Soivio, 1964), especially since the pituitary-adrenal axis is known to be blocked during hibernation in the hedgehog (Hoo-Paris, 1971). That neuroendocrine activity during spontaneous arousal plays a part in the termination of hibernation (Wang, 1982) is supported by elevated prolactin values during winter, the reactivation of the gonads during the second half of hibernation (Fowler \& Racey, 1987) and the observations of Saboureau et al. (1984) who found that exogenous testosterone in autumn abolished hibernation in hedgehogs.

The wide-ranging functions of prolactin (McNeilly, 1980; Knight \& Peaker, 1982; McNeilly et al., 1982; Bartlet, 1985; Gromdzka-Ostrowska et al., 1985) makes the interpretation of the significance of elevated prolactin values during winter difficult, although prolactin is implicated in induced ovulation (Saboureau \& Castaing, 1985) in hedgehogs. Correlations between prolactin and photoperiod and ambient temperature suggest that prolactin is involved in the environmental regulation of metabolic and reproductive cycles of the hedgehog.

Maximal thyroxin values occurring during the active season in hibernators (Saboureau \& Boissin, 1978) and non-hibernators, such as the European badger, Meles meles (Maurel \& Boissin, 1983), indicate the extensive metabolic function of thyroid hormones. The development of 
hypothyroidism in fasted rats (Bachman et al., 1985; Connors et al., 1985) is paralleled in hibernators undergoing prolonged inanition, and it is pertinent that thyroxin concentrations are basal during the first half of hibernation in the hedgehog. The rapid spring rise in thyroxin recorded in the present study has been reported for other hibernators, such as the edible dormouse, Glis glis, (Jallageas \& Assenmacher, 1983) and other heterothermic species (Cheema \& Ayyaz, 1983). The coincidence between high thyroxin utilization and elevated basal metabolic rate in the shrew Sorex vagrans (Tomasi, 1984) is seen on a circannual basis in the hedgehog (Fowler, 1986). The earlier rise in spring, and fall in autumn, of plasma thyroxin values in males than females is indicative of the males' earlier entry into, and arousal from, hibernation (Kristoffersson \& Soivio, 1964).

The circannual melatonin cycle observed in the present study is similar to that reported for other species (Reiter, 1978; Tamarkin, et al., 1985), although peak values of $800 \mathrm{pg} / \mathrm{ml}$ in the hedgehog were rather high. The high plasma melatonin concentrations at photoperiods under 10L:14D coincide with November to February, the period of deepest hibernation, although from December arousal frequency increases (Kristoffersson \& Soivio, 1964, 1967a, b) until full activity in April/May. The sudden change in melatonin secretion at 10L:14D suggests that this is a key photoperiod in the entrainment of endogenous cycles in the hedgehog, and the timing of the annual melatonin cycle suggests that it is involved in the transduction of photoperiodic cues in the hedgehog, as in many other species (Reiter, 1981a, b; Martinet \& Allain, 1985). Similarities between day and night melatonin values were probably due to accidental exposure of the hedgehogs to light when they were bled.

The plasma $\beta$-endorphin cycle observed was surprisingly similar to that recorded for a shortday breeder, the ram, by Ebling \& Lincoln (1987). However, in the hedgehog concentrations are low throughout winter and much of spring, but low until early summer in the ram. Maximal $\beta$-endorphin levels in the ram coincided with the onset of the breeding season, which would imply that elevated $\beta$-endorphin from March may be functional in the environmental modulation of hedgehog reproductive cycles. The lack of correlation of $\beta$-endorphin with plasma or urinary cortisol suggests that it is not simply secreted from the anterior pituitary simultaneously with $\mathrm{ACTH}$, as occurs in response to treatment with corticotrophin-releasing factor (Vale et al., 1978) or stress (Guillemin et al., 1977). The rise in $\beta$-endorphin values between January and March correlates with plasma testosterone and thyroxin elevation, suggesting a role for $\beta$-endorphin in both the reactivation of gonadal activity which occurs at this time (Girod et al., 1967; Walin et al., 1968; Dutourne \& Saboureau, 1983) and the stimulation of anabolism (Margules, 1979). However, the suppression of LH secretion by $\beta$-endorphin (Ebling \& Lincoln, 1985) contradicts a progonadal role for $\beta$-endorphin, although its antigonadotrophic effect is modulated by gonadal steroids themselves (Bhanot \& Wilkinson, 1984). It may be important that plasma prolactin rises before $\beta$-endorphin values fall in October.

Since serotonin inhibits hedgehog reproduction (Saboureau, 1973; Pevet \& Saboureau, 1974), the fall in melatonin levels during spring may be permissive in the sexual reactivation of the hedgehog. There is also evidence that the inhibition of gonadotrophin secretion by opioids acts via the stimulation of the release of a precursor of melatonin, and other reproductively active pineal indoles (Reiter, 1984), 5-hydroxytryptamine (Stansfield et al., 1988). Similarly, the inverse relationship between prolactin and testosterone indicates short-day stimulation of testicular prolactin receptors in the hedgehog, the opposite of events in another hibernator, the hamster (Klemcke $e t$ al., 1983). The departure of plasma testosterone concentrations from a strict correlation with the rate of change of photoperiod (Fig. 3) in July suggests that at this time hedgehogs may become photorefractory, with sensitivity to daylength returning by October/November and the 10L:14D photoperiod.

This research was supported by a SERC studentship. I thank Professor P. A. Racey for help and advice throughout the study; Dr G. E. Webley (Institute for Hormone and Fertility Disorders, Hamburg, F.R.G.), Mr G. Henderson (School of Agriculture, University of Aberdeen), Dr A. S. 
McNeilly, Dr F. J. P. Ebling and Dr G. A. Lincoln (MRC Reproductive Biology Unit, Edinburgh) and Dr P. H. Whiting (Department of Clinical Biochemistry, University of Aberdeen) for invaluable assistance with radioimmunoassays.

\section{References}

Abraham, G.E. (1969) Solid-phase radioimmunoassay of estradiol-17ß. J. clin. Endocr. Metab. 29, 866-870.

Allanson, M. (1934) Seasonal variation in the reproductive organs of the male hedgehog. Trans. Roy. Soc. Lond. 223, 277-303.

Bachman, K., Arieli, A., Burger, A.G. \& Chinet, A.E. (1985) Triiodothyronine $\left(\mathrm{T}_{3}\right)$-induced thermogenesis: altered $\mathrm{T}_{3}$ efficiency in tissues from fed, starved, and refed hypothyroid rats. Endocrinology 117, 1084-1089.

Bartlet, J.P. (1985) Prolactin and calcium metabolism in pregnant ewes. J. Endocr. 107, 171-175.

Bhanot, R. \& Wilkinson, M. (1984) The inhibitory effect of opiates on gonadotrophin secretion is dependent upon gonadal steroids. J. Endocr. 102, 133-141.

Boissin, J., Daniel, J.Y., Ixhart, G. \& Canivenc, R. (1975) Etude preliminaire des glucocorticoides chez quelques mammiferes sauvages. J. Physiol., Paris 71, $126 \mathrm{~A}-127 \mathrm{~A}$.

Brooks, A.N., Lamming, G.E., Lees, P.D. \& Haynes, N.B. (1986) Opioid modulations of LH secretion in the ewe. J. Reprod. Fert. 76, 693-708.

Cameron, I.L. \& Cleffmann, G. (1964) Initiation of mitosis in relation to the cell cycle following feeding of starved chickens. J. Cell Biol. 21, 169-174.

Cheema, A.M. \& Ayyaz, M. (1983) Heterothermic pattern of thyroid gland activity in the northern palm squirrel, Funambulus pennanti Wroughton. Pak. J. Zool. 14, 225-229.

Chesworth, J.M. (1977) Radioimmunoassays of ovine LH and ovine prolactin using polymerised second antisera. Analyt. Biochem. 80, 31-40.

Connors, J.M., de Vito, W.J. \& Hedge, G.A. (1985) Effects of food deprivation on the feedback regulation of the hypthalamic-pituitary-thyroid axis of the rat. Endocrinology 117, 900-906.

Dawe, A.R. (1978) Hibernation trigger research updated. In Strategies in the Cold: Natural Torpidity and Thermogenesis, pp. 541-563. Eds L. C. H. Wang \& J. W. Hudson. Academic Press, London.

Deanesly, R. (1934) The reproductive cycle of the female hedgehog. Trans. Roy. Soc. Lond. 223, 367-384.

Dubois, P. \& Girod, C. (1967) Observations sur l'ultrastructure des cellules antehypophysaires chez le herisson (Erinaceus europaeus L.) durant la periode hibernale. C. r. Séanc. Soc. Biol. 161, 813-816.

Dutourne, B. \& Saboureau, M. (1983) An endocrine and histophysiological study of the testicular annual cycle in the hedgehog (Erinaceus europaeus). Gen. comp. Endocrinol. 50, 324-332.

Ebling, F.J.P. \& Lincoln, G.A. (1985) Endogenous opioids and the control of seasonal LH secretion in Soay rams. J. Endocr. 107, 341-353.

Ebling, F.J.P. \& Lincoln, G.A. (1987) $\beta$-Endorphin secretion in rams related to season and photoperiod. Endocrinology 120, 809-818.
Fowler, P.A. (1986) Aspects of heterothermy and reproduction in seasonally breeding animals. Ph.D. thesis, University of Aberdeen.

Fowler, P.A. \& Racey, P.A. (1987) Relationship between body and testis temperatures in the European hedgehog. Erinaceus europaeus, during hibernation and sexual reactivation. J. Reprod. Fert. 81, 567-573.

Girod, C. \& Cure, M. (1965) Etudes des correlations hypophyso-testiculaires, au cours du cycle annuel, chez le herisson (Erinaceus europaeus). C. r. hebd. Séanc. Acad. Sci. Paris D 261, 257-260.

Girod, C., Dubois, P. \& Cure, M. (1965) Identification experimentale, en microscopie optiques et en microscopie electroniques, de cellules a prolactine antehypophysaires chez le herisson (Erinaceus europaeus). C. r. hebd. Séanc. Acad. Sci. Paris D 261, 5660-5663.

Girod, C., Dubois, P. \& Cure, M. (1967) Recherches sur les correlations hypophyso-genitales chez la femelle de herisson (Erinaceus europaus L.). Annals Endocrinol. 28, 581-610.

Gromdzka-Ostrowska, J., Mades, A. \& Barcikowski, B. (1985) Peripheral plasma prolactin concentrations during oestrous cycles in different types of primitive gilt. J. Reprod. Fert. 73, 159-164.

Guillemin, R., Vargo, T., Rossier, J., Minick, S., Ling, N., Rivier, C., Vale, W. \& Bloom, F. (1977) $\beta$-Endorphin and ACTH are secreted concomitantly by the pituitary gland. Science, N.Y. 197, 1367-1369.

Gustafson, A.W. \& Damassa, D.A. (1987) Binding sex steroids to plasma proteins: relations to androgen resistance and asynchronous reproductive patterns in hibernating bats. In Recent Advances in the Study of Bats, pp. 441-458. Eds M. B. Fenton, P. A. Racey \& J. M. V. Rayner. Cambridge University Press, Cambridge.

Halberg, F., Tong, Y.L. \& Johnson, E.A. (1967) Circadian system phase-an aspect of temporal morphology: procedures and illustrative samples. In Cellular Aspects of Biorhythms, pp. $20-48$. Ed. H. von Mayersbach. Springer-Verlag, Berlin.

Henderson, G.D. \& Chesworth, J.M. (1977) The choice of charcoal for use in steroid radioimmunoassay. $L a b$. Practice 26, 866-867.

Hoffman, R.A. \& Zarrow, M.X. (1958) Seasonal changes in the basophilic cells of the pituitary gland of the ground squirrel (Citellus tridecemlineatus). Anat. Rec. 131, 727-735.

Hoo-Paris, R. (1971) Hibernation and ACTH in the hedgehog, Erinaceus europaeus. Annls Endocrinol. 32, $743-752$.

Jalleagas, M. \& Assenmacher, I. (1983) Annual plasma testosterone and thyroxin cycles in relation to hibernation in the edible dormouse Glis glis. Gen. comp. Endocrinol. 50, 452-462.

Klemke, H.G., Bartke, A. \& Borer, K.T. (1983) Testicular prolactin receptors and growth hormone in golden 
hamsters: effects of photoperiod and time of day. Biol. Reprod. 29, 605-614.

Knight, C.H. \& Peaker, M. (1982) Development of the mammary gland. J. Reprod. Fert. 65, 521-536.

Kristiansson, H. (1984) Ecology of the hedgehog Erinaceus europaeus population in southeastern Sweden. Ph.D. thesis, University of Lund.

Kristoffersson, R. \& Soivio, A. (1964) Hibernation in the hedgehog (Erinaceus europaeus L.). The periodicity of hibernation of undisturbed animals during winter in a constant ambient temperature. Ann. Acad. Sci. Fenn. 80, 5-22.

Kristoffersson, R. \& Soivio, A. (1967a) A comparative long-term study of hibernation in Finnish and German hedgehogs in a constant ambient temperature. Ann. Acad. Sci. Fenn. 122, 1-3.

Kristoffersson, R. \& Soivio, A. (1967b) Studies on the periodicity of hibernation in the hedgehog (Erinaceus europaeus L.). II. Changes of respiratory rhythm, heart rate, and body temperature at the onset of spontaneous and induced arousals. Ann. Zool. Fenn. 4, 595-597.

Kulpa, C.M. \& Hall, K.D. (1983) Hibernation induction trigger substance from hibernation re-entering female ground squirrels (Spermophilus tridecemlineatus). Bios 54, 237-245.

Lincoln, G.A., Ebling, F.J.P. \& Martin, G.B. (1987) Endogenous opioid control of pulsatile LH secretion in rams: modulation by photoperiod and gonadal steroids. J. Endocr. 115, 425-438.

McNeilly, A.S. (1980) Prolactin and the control of gonadotrophin secretion in the female. J. Reprod. Fert. 58, 527-549.

McNeilly, A.S. \& Friesen, H.G. (1978) Heterologous radioimmunoassay for rabbit prolactin. Endocrinology 102, 1539-1547.

McNeilly, A.S., Glasier, A., Johanssen, J. \& Howie, P.W. (1982) Evidence for direct inhibition of ovarian function by prolactin. J. Reprod. Fert. 65, 559-569.

Margules, D.L. (1979) $\beta$-Endorphin and endoloxone: hormones of the autonomic nervous system for conservation of expenditure of bodily resources and energy in anticipation of feast or famine. Neurosci. Biobehav. Rev. 3, 155-159.

Martinet, L. \& Allain, D. (1985) Role of the pineal gland in the photoperiodic control of reproductive and non-reproductive functions in mink (Mustela vison). In Photoperiodism, Melatonin and the Pineal, pp. 170-187. Eds D. Evered \& S. Clark. Pitman, London.

Maurel, D. \& Boissin, J. (1983) Seasonal rhythms of locomotor activity and thyroid function in male badgers (Meles meles L.). J. Interdiscipl. Cycle Res. 14, 285-303.

Oeltgen, P.R., Walsh, J.W., Hamman, S.R., Randall, D.C. Spurrier, W.A. \& Myers, R.D. (1981) Hibernation "trigger": opioid-like inhibitory action on the brain function of the monkey. Pharmacol. Biochem. Behav. 17, 1271-1274.

Pevet, P. (1975) Vacuolated pinealocytes in the hedgehog (Erinaceus europaeus L.) and the mole (Talpa europaea L.). Cell. Tiss. Res. 159, 303-309.

Pevet, P. \& Saboureau, M. (1974) L'epiphyse du herisson (Erinaceus europaeus L.) male. I. Les pinealocytes et leur variations ultrastructureles considerees au cours de cycle sexuel. Z. Zellforsch. mikrosk. Anat. 143, $367-385$.

Ratcliffe, W.A., Challand, G.S. \& Ratcliffe, J.G. (1974) A critical evaluation of separation methods in radioimmunoassays for total triiodothyronine and thyroxine in unextracted human serum. Ann. Clin. Biochem. 11, 224-229.

Reiter, R.J. (1978) Anti- and counter antigonadotrophic effects of melatonin: an apparent paradox. In BrainEndocrine Interaction III. Neural Hormones and Reproduction, pp. 344-355. Eds D. E. Scott, G. P. Koziowski \& A. Weindl. Karger, London.

Reiter, R.J. (1981a) Seasonal aspects of reproduction in a hibernating rodent: photoperiodic and pineal effects. In Survival in the Cold: Hibernation and Other Adaptations, pp. I-12. Eds X. J. Musacchia \& L. Jansky. Elsevier/North-Holland Biomedical Press, Amsterdam.

Reiter, R.J. (1981b) Similarities in the refractoriness of the reproductive system of hamsters to melatonin and darkness. In Melatonin: Current Status and Perspectives, pp. 159-164. Eds N. Birau \& W. Schloot. Pergamon Press, Oxford.

Reiter, R.J. (1984) Pineal indoles: production, secretion and actions. In Neuroscience Perspectives, vol. 3, pp. 345-377. Eds E. E. Muller \& R. M. MacLeod. Elsevier Science Publishers, London.

Roberts, A.C., Martensz, N.D., Hastings, M.H. \& Herbert, J. (1985) Changes in photoperiod alter the daily rhythms of pineal melatonin content and hypothalamic $\beta$-endorphin content and the luteinising hormone response to naloxone in the male Syrian hamster. Endocrinology 117, 141-148.

Saboureau, M. (1973) Effets de la serotonine et de la melatonine sur l'appareil genital du herisson male (Erinaceus europaeus L.) au cours de la periode d'activite sexuelle. C. r. Séanc. Soc. Biol. 167, 712-717.

Saboureau, M. (1979) Cycle annuel du fonctionment testiculaire du herisson (Erinaceus europaeus L.). Sa regulation par les facteurs externes et internes. These Doct. es Sciences, Université de Tours.

Saboureau, M. (1981) Environmental factors and regulation of the annual testicular cycle in a breeding hibernating mammal: the hedgehog. In Photoperiodism and Reproduction in Vertebrates, $\mathrm{pp}$. 319-337. INRA, Nouzilly.

Saboureau, M. \& Boissin, J. (1978) Variations saisonnieres de la testosteronemie et de la thyroxinemie chez le herisson (Erinaceus europaeus L.). C. r. hebd. Séanc. Acad. Sci. Paris 286, 1479-1482.

Saboureau, M. \& Boissin, J. (1983) Peripheral metabolism of testosterone during the annual reproductive cycle in the male hedgehog, a hibernating mammal. Can. J. Zool. 61, 2849-2855.

Saboureau, M. \& Castaing, L. (1985) Hibernation and reproduction in the female hedgehog. In Endocrine Regulations as Adaptive Mechanisms to the Environment, pp. 191-208. Eds I. Assenmacher \& J. Biossin, CNRS, Paris.

Saboureau, M. \& Dutourne, B. (1981) The reproductive cycle in the male hedgehog (Erinaceus europaeus L.): a study of endocrine and exocrine testicular functions. Reprod. Nutr. Develop. 21, 109-126. 
Saboureau, M. \& Peyre, A. (1970) Le decalage des activites endocrine et spermatogenique du testicule au cours du reveil printanier chez le herisson male. $C$. r. Séanc. Soc. Biol. 164, 2364-2367.

Saboureau, M., Laurent, G. \& Boissin, J. (1979a) Daily and seasonal rhythms of locomotor activity and adrenal function in male hedgehogs. $J$. Interdiscipl. Cycle Res. 10, 249-266.

Saboureau, M., Bobet, J.P. \& Boissin, J. (1979b) Activite cyclique de la fonction corticosurrenalienne et variations saisonnieres du metabolisme peripherique du cortisol chez un mammifere hibernant, le herisson (Erinaceus europaeus, L.). J. Physiol., Paris 76, 617-629.

Saboureau, M., Laurent, A.M. \& Boissin, J. (1982) Plasma testosterone binding-protein capacity in relation to the annual testicular cycle in a hibernating mammal, the hedgehog (Erinaceus europaeus L). Gen. comp. Endocrinol. 47, 59 63.

Saboureau, M., Castaing, L. \& Boissin, J. (1984) Influence de taux plasmatique de testosterone et du jeune sur les variations automnales et hivernales de l'activite motrice generale du Herisson, Erinaceus europaeus L. C. r. hebd. Séanc. Acad. Sci. Paris D 299, 239-244.

Saure, L. (1969) Histological studies on the sexual cycle of the male hedgehog (Erinaceus europaets L.). Aquilo Ser. Zool. 9, 1-43.

Shiotsuka, L.A., Jovonovich, J. \& Jovonovich J. (1974) Circadian and ultradian corticosterone rhythms in adrenal organ cultures. Chronobiologia, Suppl. 1, 109-121.

Snedecor, G.W. \& Cochran, W.G. (1980) Statistical Methods, 7th edn, pp. 149-174. Iowa State University Press, Ames.

Stansfield, S.C., Knight, P.G., Hawkes, C.M. \& Cunningham, F.J. (1988) Endogenous opioid peptide modulation of LH secretion in the ewe lamb: possible involvement of 5-hydroxytryptamine. J. Endocr. 116, 403-411.

Tamarkin, L., Baird, C.J. \& Almeida, O.X.F. (1985) Melatonin: a coordinating signal for mammalian reproduction? Science, N.Y. 227, 714-720.

Teravainen, T. \& Saure, A. (1976) Changes in the testicular metabolism of dehydroepiandrosterone during the annual cycle of the hedgehog (Erinaceus eruopaeus L.) Gen. comp. Endocrinol. 29, 328-332.

Tomasi, T. (1984) Shrew metabolic rates and thyroxine utilisation. Comp. Biochem. Physiol. 78A, 431-435.

Vale, W., Rivier, C., Yang, L., Minick, S. \& Guillemin, R. (1978) Effects of purified hypothalamic corticotropin-releasing factor and other substances on the secretion of adrenalocorticotropin and $\beta$-endorphinlike immunoreactivities in vitro. Endocrinology 103, 1910-1914.

Walin, T., Soivio, A. \& Kristoffersson R. (1968) Histological changes in the reproductive system of female hedgehogs during the hibernation season. Ann. Zool. Fenn. 5, 227-229.

Wang, L.C.H. (1982) Hibernation and the endocrines. In Hibernation and Torpor in Mammals and Birds, pp. 206-236. Eds C. P. Lyman, J. S. Willis, A. Malan \& L. C. H. Wang. Academic Press, London.

Webley, G.E., Mehl, H. \& Willey, K.P. (1985) Validation of a sensitive direct assay for melatonin for investigation of circadian rhythms in different species. $J$. Endocr. 106, 387-394.

Wimsatt, W.A. (1969) Some interrelationships of reproduction and hibernation in mammals. Symp. Soc. exp. Biol. 23, 511-549.

Zar, J.H. (1984) Biostatistical Analysis, 2nd edn, pp. 162-184. Prentice-Hall Inc., Englewood Cliffs.

Received 25 January 1988 